\title{
BOLIVIA, LA OTRA QUE QUIERO Y QUE EMPEZABA A DESCONOCER Reflexiones en torno al Informe de Desarrollo Humano en Bolivia 2000
}

\author{
Luis Verdesoto Custode*
}

Fecha de recepción: agosto 2000

Fecha de aceptación y versión final: septiembre 2000

Resumen: El artículo -que comenta el Informe Desarrollo Humano de Bolivia 2000- se pregunta ¿qué significa globalizarse para un país? ¿Es posible medirla desde las dimensiones subjetivas de la interacción social? ¿Cuáles son los límites de la modificación de la "personalidad social" de las naciones? Para proyectarse en el mundo globalizado es necesario interactuar desde la definición de los intereses "propios". Hay que definir los cambios en los paradigmas de la subjetividad para asumir la comparación y examinar las aptitudes para conservar y modificar a la nación. En suma, ¿Estamos construyendo formas específicas de ser en la globalización? La forma de entendernos en los "poderes" de la globalización es disponer de un arsenal mínimo de "saberes". Es una medición de la autonomía para relacionarse. Permite "negociar" la inserción en la globalización, que plantea las formas de una construcción conjunta y conflictiva de los sentidos de la historicidad (compromisos). Acerca de las tareas pendientes, en el ámbito político, el artículo sostiene que deben fortalecerse las instituciones: cuando la sociedad asedia con su dinámica contradictoria, las instituciones no pueden construir su lógica valórica. En el ámbito económico, debe re-enrumbarse el sentido de la competitividad: ¿Se puede conducir la eficiencia hacia la solidaridad? En el ámbito social, debe superarse la extrema pobreza: existe una enorme incapacidad para producir un pacto nacional contra la pobreza ya que los pactos políticos no tienen pactos sociales de sustento.

La educación aparece como la posibilidad de (re) conocer a la inserción internacional como una oportunidad. Es una apuesta por la ciudadanización, ejercicio de la capacidad de elección de los usuarios de la democracia. La utilización de las instituciones de la democracia está sustentada en la implantación ininterrumpida de la ciudadanía. Para que los valores sean parte del desarrollo deben ser plurales y reconocerse en el sentido histórico de cada sociedad. El autor propone que se debe descubrir el tipo de asociación entre lo racional y lo afectivo tanto como conseguir una definición de individuación así como también puntualiza respecto al papel que las elites dirigentes desarrollan en esos procesos.

Palabras clave: Informe de Desarrollo Humano, Sociedad Civil, efectos de la globalización, Bolivia.

Abstract/Summary: The article -which discusses the Report on Human Development in Bolivia 2000- questions what does globalization mean for a country? Is it possible to measure it from the subjective dimensions of social interaction? What are the limits to the alteration of the "social personality" of nations? In order to be projected into the globalized world it is necessary to interact starting from the definition of "self" interests. It is necessary to define the changes in the paradigms of subjectivity to take upon the comparison and examine the aptitudes to preserve and modify the nation. In short, Are we building specific ways to be at the times of globalization? The way to understand ourselves within the "powers" of globalization is to have a minimum arsenal of "knowledge". It is a measure of the autonomy to relate to others. It allows you to "negotiate" the insertion inside globalization, which sets the ways of a joint and conflictive construction of the directions of historicity (commitments). With respect to the remaining tasks, in the political field, the article states that institutions should be strengthened: when society besieges them with its contradictory dynamics, institutions cannot build their valuing logic. In the economic field, should the sense of competitiveness be redirected: Can efficiency be directed towards solidarity? In the social field, extreme poverty must be overcome: there is a huge inability to arrive to a national agreement against poverty, since political agreements do not have supporting social agreements.

Education comes out as the possibility to (re)cognize international insertion as an opportunity. It is a wager for citizenship, an exercise of the ability to elect the users of democracy. The use of the institutions of democracy is supported by the uninterrupted establishment of citizenship. In order for values to become part of development they should be plural and should be acknowledged within the historical sense of each society. The author suggests that the type of association between the rational and the affective should be discovered, as well as getting a definition of individuation, the role that the leading elite classes carry out in these processes is mentioned also.

Key words: Report on Human Development, civil society, globalization effects, Bolivia. 
En nuestro hacer, no existe obligación más grata que comentar un libro con ideas de fondo, escrito en clave sociológica, como lo manda el "oficio" '. Es más interesante, cuando me permitió volver la cabeza hacia Bolivia y leerla desde sus entrañas. Leerla, además, desde otras realidades, que nos permiten ver y vernos. Me estacioné en Bolivia, por primera vez, cuando se expedía el $21060^{2}$. Pude sentir la "muerte sociológica" de una clase -los mineros- y pude mirar como, desde entonces, intenta ser liberal una sociedad vigorosamente centrada en la nación.

Este artículo tiene un carácter ensayístico. Salvo poquísimas excepciones, no se citan los textos, de los cuales, sin embargo, el comentario sigue siendo tributario ${ }^{3}$. El texto no puede sustraerse de debates e interlocuciones que tienen muchos años. A un texto abigarrado, como lo es el Informe, no puede respondérsele con invocaciones a la "buena lectura". Son años de debates y divagaciones, angustiosas y fructíferas, que quisieron hacer de las letras, acciones; de las propuestas, instituciones; de las ideas, democracia.

Es muy importante que el libro tenga origen en un organismo internacional. La aparente homogeneidad de metodologías, siempre se reinventa. El texto de origen -los Informes de Desarrollo Humano- son propuestas mundiales de ideas fértiles. Nuestra obligación es la irreverencia creativa.

Los siguientes párrafos no son sino un homenaje más, a una realidad que me dice mucho, y que me ha permitido ser parte de sus dolores y logros.

\section{UNO}

1.- ¿Qué significa globalizarse para un país? ¿Es posible "medir" a la globalización desde las dimensiones subjetivas de la interacción social? ¿Puede la sociedad tener a sus valores como el mejor instrumento para asumir a la globalización? Estos son los temas-retos del Informe. Ahora bien, ¿para qué/para quién es útil preguntarse sobre la globalización de un país? Esta pregunta se contrapone a las alianzas anti-modernizadoras que se plantean, ¿cuánto podemos resistir a la globalización?

De entrada, el Informe nos devuelve a las preguntas clásicas de la Sociología y de la Sociología Política acerca de las bases sociales de la democracia; a las determinaciones centrales del desarrollo. Finalmente, el tema son las relaciones entre comunidad -sociológicamente definida- y destino -definido por imágenes de historia y coyuntura-.

2.- Las "definiciones de sí mismo". Un país es una "personalidad social", entendida como un conjunto de comportamientos y de rasgos construidos en el tiempo que actúan tanto en el pasado como en el presente; es la ubicación de actores frente a sus destinos o la pérdida de la ubicación de la sociedad frente a lo que ella $-\mathrm{u}$ otros- definen como sus estándares. La pregunta pertinente sigue siendo, ¿si la "personalidad social" de las naciones se modifica y cuáles son los límites de ese cambio? Dicho de otro modo, se asume que la globalización es un fenómeno de un poder pro-activo tan formidable, que incluso provoca redefiniciones, empujadas por los actores sociales y las políticas públicas, las que sobrepasan a la mera descomposición de la personalidad social sino que asumen nuevos contornos y, presumiblemente, nuevos contratos.

3.- Los paradigmas. Para un país, proyectarse en el mundo globalizado es, necesariamente, asumir una interacción compleja con otros sujetos, de desigualdad de poder e intereses. Esta proyección tiene que hacerse con instrumentos cada vez más estandarizados, pero desde la definición de los intereses "propios". Todos los días el mercado mundial nos muestra definiciones de ello.

Volviendo al principio. Se trata de definir los cambios que operan en los paradigmas de la subjetividad boliviana, en tanto, por un lado, instrumentos de articulación a otros globalizados (o en trance de globalización) y forma de asumir la comparación (o las "ventajas comparativas"); y, por otro lado, examinar las aptitudes para conservar a la nación en su estado actual.

En corto, nos preguntamos ¿Están los bolivianos (y en este sentido los ecuatorianos o los dominicanos) construyendo formas específicas de ser en la globalización? ¿ $\mathrm{O}$ es que acaso se han allanado a los cambios perdiendo sentido nacional? ${ }^{4}$.

4.- Los poderes de la globalización. La forma de entendernos en los "poderes" de la globalización es disponer de un arsenal mínimo de "saberes" sobre nosotros mismos y sobre los otros -instrumentos de conocimiento-y de una medición -confiable- de los cambios nacionales, internacionales y mundiales, referentes sin los cuales no se puede actuar. La disparidad medida por los indicadores tradicionales (económicos, sociales, territoriales, genéricos) se pondera hacia arriba por la disparidad en la capacidad cognoscitiva y tecnológica. La desigualdad tecnológica es una distancia gigantesca que sigue creciendo contra nosotros.

Sin embargo, existen instrumentos más apegados a los conocimientos, que permiten "negociar" (mejor o algo) la inserción en la globalización. No podemos negar nuestro derecho a un discurso acerca de la globalización, a una medición de la autonomía con que la que nos relacionamos y a una visión de la comunidad de la que seguimos siendo parte. Sin asumir este supuesto, no podemos ser parte de una "negociación" en la globalización". Dicho de otro modo, solamente si los bolivianos entienden su propia problemática-y las dimensiones de la transformación de su personalidad social- podrán asumir, en clave positiva, a la globalización como una oportunidad.

1. El equipo que elaboró el Informe fue coordinado por Fernando Calderón.

2. El Decreto Ejecutivo 21060 fue expedido en enero de 1986 por el gobierno del Dr. Víctor Paz Estensoro y contiene una propuesta de liberalización y apertura de la economía y sociedad bolivianas.

3. Todos los entrecomillados del texto pertenecen al Informe de Desarrollo Humano en Bolivia 2000.

4. ¿Por qué un país como Ecuador - uno de los más lejanos del mundo por su bajo relacionamiento internacional- instrumenta una globalización compulsiva a través, por ejemplo, de la “dolarización” de su economía y de la renuncia de muchos atributos de política económica?

5. Poco se obtiene al constatar la disparidad Bolivia-Japón, por ejemplo, si un país no se pregunta sobre las definiciones "desde las cuales" se negocia la disparidad. 
El Informe se plantea este reto y esta "mirada" desde la cual asumir la medición de las disparidades clásicas del desarrollo humano.

5.- La soberanía. Perder o redefinir la soberanía, no hay otra alternativa. El Informe asume, casi como un principio, la pérdida relativa de soberanía. Esto es así, mirada la soberanía desde la dimensión territorial tradicional. Dentro de estos parámetros, sólo es posible pensar a la soberanía desde la dimensión de la autonomía absoluta y a su reducción como la consecuencia necesaria de los cambios.

Antes bien, cabe afirmar, que sí es posible pensar a los múltiples clivajes de la autonomía en la actualidad, los que conducen a la soberanía como dimensiones que se modernizan y complejizan, con un más allá y un más acá de la autonomía absoluta. Las interrelaciones e interdependencias cada vez más refieren a una gama de variables en que el territorio, fuente de un planteamiento de exclusión de terceras posiciones, cada vez pesa menos dentro del conjunto. A su vez, las mentalidades de los sujetos sociales asumen crecientemente a los nuevos vínculos como lenguajes para reproducirse a sí mismos. La globalización de los mercados y de los componentes culturales plantean las formas de una construcción conjunta y conflictiva de los sentidos de la historicidad ("construcción de compromisos").

6.- Los hilos de la mundialización. Ciertamente, la mayor influencia de la globalización opera a través de las instituciones y las prácticas financieras. El rol central de intermediación (y de la referencia de todos los intercambios) sigue siendo el dinero y la decisiva capacidad del financiamiento para la asignación de los recursos. Sin caer en la trampa de reducir la sociedad a las "medidas" de los economistas, es evidente que el dinero -y el financiamiento- han convertido a "sus" instituciones, en el síntoma de la fragilidad de "todas" las instituciones. La vulnerabilidad de la sociedad a las crisis financieras en varios países de la región (y con más dolor por lo cercano y lo reciente el Ecuador), muestra el tipo y el grado de penetración de los intercambios para la definición de la personalidad social.

7.- Los compromisos en la globalización. La naturaleza más elemental que adquieren los compromisos entre diferentes en la globalización suele ser la "condicionalidad" (de la cooperación, del comercio, de la apertura, etc). La condicionalidad supone asimetría y una racionalidad no compartida (la simetría y la racionalidad común harían innecesaria a la condicionalidad). A su vez, la condicionalidad libera a la interdependencia de su característica de comprensión del otro y la devuelve a su plano original de dependencia. $\mathrm{Y}$ la dependencia se basa en el conocimiento de los objetivos e intereses de uno, que supone objetivos e intereses del otro reductibles a los propios. Incluso se puede suponer la existencia de objetivos e intereses comunes, pero cuya construcción está determinada por la racionalidad del que detenta recursos.

Las Cartas de Intención o la Cooperación para la eliminación de la pobreza -básicamente distintas- son actos de una racionalidad externa a nuestros países, cuya creación de vínculos con las diversidades internas, están finalmente sentadas en la imposición a las elites, la desestructuración de los subordinados o la pérdida de la racionalidad sustantiva de las instituciones. En el fondo, la urgencia por convertir a la necesidad en orden, puede convertir el respeto a la diversidad, en que debería sustentarse la confianza entre los interdependientes, en imposición de propósitos tales como el buen gobierno.

8.- Las tareas. El Informe plantea tareas centrales sin las cuales la estabilidad económica no es sustentable. Cada una corresponde a un ámbito clásico de las formaciones históricas. Así, en el ámbito político deben fortalecerse las instituciones; en el ámbito económico debe re-enrumbarse el sentido de la competitividad; y, en el ámbito social debe superarse la extrema pobreza. Examinemos cada uno de ellos.

Las instituciones bolivianas, especialmente las estatales, nunca pudieron construir su propia lógica valórica y sus rutinas para el procesamiento de los temas que les corresponden, porque estuvieron sometidas al asedio de la sociedad y de sus lógicas contradictorias, que compartían en común, el irrespeto institucional. La "apuesta" (recomendación) primordial del Informe se enrumba hacia la cultura institucional, basada en la educación ciudadana y social. Sin embargo, evade la segunda parte de la "apuesta", posiblemente, porque asume, de partida, una respuesta. Esto es, que el tema parece no ser una disyuntiva entre el rediseño institucional o la modificación de los sujetos portadores de las instituciones, sino la mutua necesidad entre los dos procesos. Más aun cuando, como en el caso boliviano, operan sobre una base nacional tan sólida como rígida.

Entre los objetivos de la competitividad está el logro de la eficiencia. La pregunta permanente es ¿Se puede conciliar solidaridad y eficiencia? O, planteado de otro modo, ¿Se puede conducir la eficiencia hacia la solidaridad? De un lado, el problema parece ubicarse en el modo de cómo la búsqueda de eficiencia económica conduce a abigarradas dualidades entre lo moderno y lo tradicional; entre lo interno y lo externo. De otro lado, la eficiencia debería corresponder a la creciente responsabilidad que deben asumir los productores para la generación y administración de las necesidades básicas.

En nuestros países, cada vez con más frecuencia se constata una enorme incapacidad para producir un pacto nacional contra la pobreza. Muchos factores convergen en estas imposibilidades. En Bolivia, uno de ellos, es que la posibilidad de acuerdos contra la pobreza está limitada: la estabilidad económica se asienta sólo en un pacto político sin un pacto social de sustento. De este modo, la interacción básica y el mutuo condicionamiento entre la política económica y la política social no encuentra sentido como gestión pública de la sociedad y de los decisores".

6. Una pequeña digresión. Estamos frente a la "vieja” y siempre renovada búsqueda de organicidad entre el sistema político y el sistema social, que es legítima como actividad de conocimiento y como actividad política. El actual problema de Bolivia y de otros países es que para la construcción de la referida organicidad, debe "descubrirse" la ecuación social de sustento de la política que se ha implantado, para lo cual también -y con más fondo- debe conocer ¿Quiénes son los "nuevos" sujetos sociales de la 
Desde estas dimensiones, el Informe nos obliga a reflexionar sobre la construcción social de la subjetividad boliviana, esto es pensar, de un lado, la construcción de las legitimidades -o los obstáculos a esa construcción- de la democracia; y, de otro lado, al aporte de los sujetos a las prácticas de la sociedad, su economía y su política, a la que nos hemos referido antes. Se trata de conocer los valores -culturas política e institucional- y las aspiraciones -voluntades-; los soportes subjetivos de la acción política, del ser orgánico de la sociedad y de sus partes?

9.- Las capacidades. Antes de volver sobre la construcción de la organización de la sociedad -con que "cabeza" se moviliza este "cuerpo" ${ }^{8}$, la introducción del tema de la educación, recoge el ya clásico descubrimiento de que el incremento de los niveles educativos asegura una inserción favorable en la globalización. Esto nos recuerda la movilidad social asociada a la educación, tan presente en la región hace cuatro o cinco décadas.

Pero la referencia es otra. Un país con un alto índice de analfabetismo -como fue Bolivia hasta hace dos décadas-y tan altamente conflictivo/deliberativo -que casi no pudo estructurar un orden estatal-, la educación aparece como la posibilidad de (re) conocer-conocer otra vez-el sentido de la inserción internacional como una oportunidad. La utilización de la oportunidad está ligada a la justicia tanto en el tratamiento del sistema internacional cuanto en la capacidad para demandarlo, que son capacidades nacionales -ecuaciones de desarrollo con proyectos-.

La apuesta por la ciudadanización de nuestros países estuvo ligada a que la lucha contra el analfabetismo se presente públicamente como un acto cada vez más deliberado y menos espontáneo. Esta posibilidad de ejercicio de la capacidad de elección -de usuarios de la democracia- solamente es posible si se dan dos condiciones, indispensables éstas en todo proceso educativo.

De un lado, un nivel de desarrollo que permita verificar la oportunidad como una opción viable de progreso. De otro lado, que las estructuras institucionales estén garantizadas por el sentido más profundo de la legitimidad de la sociedad. En suma, que la capacidad de utilización de las instituciones de la democracia esté necesariamente sustentada en la implantación ininterrumpida de la ciudadanía en la democracia.

10.- Las aspiraciones. "Las aspiraciones son metas futuras socialmente construidas a partir de la relación que las personas establecen con otros sujetos distintos en un contexto socio cultural específico.... Las aspiraciones son una construcción social subjetiva en la que interviene la visión presente y la perspectiva de futuro del sujeto o la comunidad", dice el Informe.

Así, el pasado fija parámetros; la sociedad los arrastra y los proyecta hacia el futuro en un ejercicio de modificación (nivel de aspiración - metas); futuro y pasado actúan en el presente permitiendo a los sujetos vivir (sentido de) y actuar (elaborar estrategias). El presente es la única dimensión temporal que permite "medir" los valores; más precisamente, la construcción de los valores.
El presente es una dimensión caótica y ordenada. Por un lado, re-construye el pasado y re-genera otro orden hacia el futuro. Esta transición entre órdenes es -no puede ser de otro modo- "caótica". La mirada del desarrollo humano puede dar un sentido de progreso o retroceso; de modernidad o modernización. Escrutar la construcción actual de la subjetividad permite conocer el lindero entre la aceptación y el uso de las instituciones. Así, se acepta lo que se adecua a formas ideales y se usa lo que presenta factibilidad para verificar intereses.

El ámbito de verificación de las aspiraciones es la garantía de instituciones que permiten el ejercicio de derechos. El tema central es el desplazamiento del eje de funcionamiento de las sociedades desde el "estado-centrismo" como forma pública de constitución de los sujetos sociales al predominio del mercado. La incertidumbre que proporciona el mercado (la "cultura de mercado") sólo puede ser contrapesada con la rutina, solidez y continuidad institucional. El futuro de las sociedades sólo existe en vínculo con las instituciones y la capacidad de modificación de la personalidad de las sociedades como sus sustentos y sus usuarias.

11.- Los valores. El Informe sostiene -indirectamenteque para que los valores sean parte del desarrollo deben ser plurales y reconocerse en el sentido histórico de cada sociedad. El reto que se plantea es desarrollar una técnica para medirlos, lo que supone una metodología para discriminar a sus partes.

Lo primero que plantea el Informe es descubrir el tipo de asociación entre lo racional y lo afectivo. Lo segundo es conseguir una definición de individuación.

Comencemos por esta segunda definición. Nuestras sociedades -me refiero a la región- fueron construidas a través de sucesivos hitos colectivos. Más precisamente, nuestro sentido de comunidad como "andinos" se produjo a través de episodios fundacionales masivos. Nuestra "virtud" está asociada con un sentido colectivo de solidaridades no mercantiles, que generan cohesiones políticas, culturales y simbólicas. Esto origina un doble estándar entre un funcionamiento colectivo dirigido hacia la comunidad y un funcionamiento individual dirigido hacia el mercado. Esta dualidad del funcionamiento social debe conciliarse a un doble nivel.

De un lado, la conformación del sentido individual de la demanda, garantía y consecución de los derechos es una tarea actual para conciliar con el sentido histórico de la construcción colectiva previa. De otro lado, debe producirse una clara individuación de los actores sociales para lograr su identificación con roles precisos dentro del sistema político-susceptibles del control social y de la rendición de cuentas- y con aportes claros a la nueva complejidad con que opera el sentido público actual.

democracia cuya subjetividad ocupa un lugar intermedio de la sociedad en relación a las prácticas económicas y políticas?

7. En este tema es pertinente revisar los 6 primeros números de las Revista Tinkazos, Revista Boliviana de Ciencias Soc iales y los resultados de las investigaciones promovidas por el Programa de Investigación Estratégica en Bolivia, PIEB.

8. Es otra lectura del Informe. 
El sentido individual del derecho y la individuación de roles en el sistema político permitirá a la sociedad dotar de interlocutores al proceso de concertación social. A su vez, los interlocutores estarán provistos de conciencia y espontaneidad. Desde esta perspectiva, la construcción de sentidos nacionales -avance del conjunto en el logro de una metacombina por necesidad, racionalidad y pasión. Discriminar metodológicamente en la construcción valórica a los componentes racionales de los pasionales, los concientes de los espontáneos, supone una gran disposición de instrumentos para la inmersión en la realidad. Esta es una tarea a medio plazo del equipo del Informe.

12.- "Nación moderna". Sucintamente, la definición del Informe puede ser codificada como comunidad heterogénea de ciudadanos. Así, la nación es una abstracción de rango intermedio, que equidista del "alto nivel" de la comunidad y del "bajo nivel" del país múltiple de indios y cholos, obreros y campesinos, terratenientes y oligarcas. Entre los actores sociales de la diferencia y la conformación de lo común político con forma de Estado, puede situarse la ciudadanía en sus dos versiones coetáneas, de comunidad política y de identidad social. Desde este punto de vista, la ciudadanía ya no es una sola forma valórica -la superación de la diferencia en la individualidad del voto- sino la tensión organizada y armónica de vertientes democráticamente articuladas. Lo común en la nación moderna son metas de destino articuladas por la "igualdad en la diferencia", aporte central en el Informe.

La drástica propuesta de eliminar del Estado boliviano toda forma de homogeneidad forzosa -religiosa, política, idiosincrática, social, cultural- debe traducirse en una lenta acción, simultánea con la reforma valórica-moral- de la sociedad boliviana. Ningún actor, ni ideología es propietario del destino nacional.

13.- ¿Qué comparten los bolivianos en la producción de su nación moderna?

Comencemos por el lado negativo. La identidad definida por el otro - las derrotas del Chaco y del Pacífico"- muestra una clave del funcionamiento político, persistente en varios países con definiciones colectivistas de sus derechos, donde el Estado es el centro de la política y de la reivindicación ${ }^{10}$. La dificultad para asumir una definición nacional en clave positiva oculta el grado de conformación de lo común de la sociedad, limita las iniciativas y "vivifica" al país, más en los tiempos de crisis que en los de bienestar y emprendimiento ${ }^{11}$.

El "pesimismo, la baja autoestima y el sectarismo" son expresiones, adicionalmente a las planteadas por el Informe, de la asunción del subdesarrollo bajo la forma nacional de la opresión. La "conciencia" de nación oprimida genera los dos polos de reivindicación permanente y la devaluación colectiva.

El Informe propone que "el sacrificio, la solidaridad y la capacidad de organización" compensan aquella forma nacional devaluada. Cabe acompañar a la afirmación que esos valores "solos" no generan por sí mismos la compensación a la devaluación colectiva, sino a través de estructuras públicas que permitan asir estas voluntades, hasta entonces, sólo son formas individuales o de localidad ${ }^{12}$.

Además, el Informe llama "debilidad de un proyecto letrado" -suponemos que refiere a la ilegitimidad de las elites que lo portaron- a la imposibilidad de articular nación y cultura. Estos son temas que generan la aversión de los economistas simples. ¿Por qué preguntarse por la nación y la cultura en un país de carencias materiales tan acentuadas? El desarrollo no tiene respuesta -además en un mundo de pocas alternativas económicas- sin una definición precisa de la ecuación socio-nacional desde la cual se lo demanda.

El tema de la integración social es definido en el Informe como búsqueda de "equidad de oportunidades en el mercado, dignidad y reconocimiento social”. Lo justo debe ser una construcción colectiva, que como producto de su deliberación genera sentido, plantea el Informe. “....concepto de igualdad compleja, que es la construcción de una comunidad política y de la misma política como fuerza constructiva de la deliberación y de la igualdad”.

El concepto de integración social remite a la búsqueda de "solidaridad orgánica" basándose en la diferenciación de roles dentro de una mediación institucional. El paso básico pareciera consistir en una división del trabajo más desarrollada, a la que se adhiere un intercambio más generalizado de pareceres e ideologías, esto es, la opinión pública. Constituir a la opinión en una parte de lo público y producir un activo intercambio es lo "civilizado" de la sociedad, ámbito de intercambio o de deliberación. El producto del intercambio es la legitimidad, única fuente constructora de igualdad sustentable y no como mera manipulación política o de las políticas públicas.

Ahora bien, ¿Qué tipo de "igualdades" tiene delante la sociedad como opciones?

14.- Estado y mercado. La transición en el desarrollo genera una incertidumbre que puede ser resuelta por terceros -los populismos emergentes- o por los propios actores a través de voluntades públicas y políticas. Las alianzas modernizadoras hasta ahora se definen por la imposición mercantil en tanto que las alianzas anti-modernizadoras se definen por suprimir cualquier rol al mercado. Desde ninguno de los dos lados, la sociedad puede poner en ejercicio su capital social transmitiendo capacidades, confianzas y vigores colectivos para una construcción nacional que permita avanzar a todos.

La reconformación del sentido de lo público en nuestras sociedades está fuertemente vinculada con amplias búsquedas en torno al Estado y al mercado. Muchas de esas búsquedas desvían su camino al producir o reproducir equi-

9. Se trata de las guerras sostenidas con Paraguay y Chile respectivamente.

10. En especial, los países del área andina.

11. El caso más reciente de la región es el ecuatoriano, en que la crisis ha puesto al país de cara a sus definiciones básicas, cuando se han roto sus principales acuerdos fundacionales.

12. Esta es la comprensión que desarrolló la Ley de Participación Popular (1994), que inicialmente recogió la vocación de aporte del pueblo boliviano y pretendió encaminarla hacia la eficiencia por la vía de la política pública. 
librios, mientras que la temática central está en una nueva articulación entre ellos; en modelos de articulación colaborativa que permitan eficiencia y derechos, transparencia y resultados.

\section{DOS}

1.- Las elites, la sociedad y la demanda del mercado. ¿Cuánto, las elites, necesitan de la sociedad -de sus valores, de sus sujetos, de su disposición- durante la transición de modelo de desarrollo como la que vive Bolivia? ¿Cuáles son los compromisos que las elites dirigentes pueden asumir con la nación durante esa fase? ¿Necesitan las elites de la sociedad durante las fases de estabilidad, las que otorgan certezas acerca del futuro? ${ }^{13}$. El compromiso que actualmente se demanda a las elites dirigentes en Bolivia puede tener varias lecturas simultáneas.

De un lado, ha sido usual demandar a los empresarios acciones precisas que no entorpecieran y favorecieran la transición tales como estabilidad de precios, aportes a la capitalización de sectores específicos, aceptación de tasas de rentabilidad. En este sentido, se apela a su sentido de elemental prospectiva y a un intercambio entre la actual reducción de beneficios y su resarcimiento de utilidades en el futuro. Es decir, se acude a una programación económica con rangos de certidumbre.

¿Qué es la certidumbre económica? La certidumbre no son sólo los agregados macroeconómicos sino esos agregados asentados en consensos sociales maduros y en consolidaciones institucionales. Es posible concluir, entonces, que el riesgo económico no es solamente individual sino, de alguna manera, compartido entre los distintos tipos de elites y segmentos de la sociedad.

De otro lado, las elites demandan del Estado políticas publicas adecuadas a la transición tales como flexibilidad laboral, focalización de subsidios, reducción y ordenamiento del gasto público. La paradoja es que el Estado sigue siendo el eje de la transición y que el compromiso empresarial no guarda armonía con un discurso "principista" anti-estatal. El sentido funcional del Estado no alcanza a conformar valores y compromisos en los empresarios. Los compromisos sectoriales a los que arriban, solamente se consiguen bajo directo control del aparato por parte de los empresarios, desvirtuándose la naturaleza misma de la representación.

Las ideas de intermediación y de recodificación de las demandas se devalúan cuando las elites corporativizan a la gestión pública. Generalmente, las elites no han podido "reconocer" a la conformación institucional de la sociedad, ni del sistema político, menospreciando la legitimidad social. La posibilidad del compromiso se disuelve ante un sentido del interés privado, excluyente de las transacciones/acuerdos y de la vocación pública. En estas circunstancias, el soporte para la orientación de comportamientos de que debe dotarse el Estado, especialmente para la transición, queda reducido a sus factores instrumentales. Y, en la sociedad, el Estado queda sujeto por la correlación de fuerzas.

Esto del lado de los obstáculos a los compromisos empresariales que el Informe insinúa como viables, luego de la revisión de la información empírica que ha recuperado. Examinemos otros ángulos del problema.

2.- ¿Cuáles son los valores de las elites dirigentes? ¿Se han modificado estos valores durante la transición? ¿Cuan flexibles son los valores para modificarse a instancias de los cambios sociales? ¿La nueva forma del desarrollo supone sujetos sociales que son vistos por las elites desde otros ángulos o necesidades? ¿Cómo se construye el aporte de los valores de las elites a la forma concreta del desarrollo que adoptan nuestros países?

El Informe nos responde a las anteriores preguntas (las que están imbuidas de razonamientos clásicos en América Latina) desde otra serie de preguntas de vocación empírica: ¿Si realmente existen las elites, cuáles son su proximidad al desarrollo humano, sus estrategias territoriales, su disponibilidad frente a la democracia deliberativa y al aprovechamiento de ventajas comparativas?

Sin decirnos explícitamente por qué, el Informe concreta la investigación de las elites en las regiones. Pudo hacerlo por sectores. $\mathrm{Al}$ asumir a las regiones como variable definitoria del corte, supone, de un lado, que la conformación territorial de las elites es más importante y significativa que la conformación sectorial. De otro lado, supone que la región - formación social en que el territorio no es solamente un referente - es la ecuación social desde la cual se mira la nación y la globalización. Además de compartir el supuesto, es importante insistir que en la ética (en su amplio sentido) de las elites, el sistema valórico regional es fuertemente productivo e institucional.

3.- Empresas y modernización. Lo primero que nos plantea el Informe, es que las elites viven una dualidad acerca de su carácter dirigente. Quiero leer la afirmación desde su invocación literal, la duda de sentirse parte de la viabilidad de Bolivia como comunidad productiva y de consumo. Pero también quiero leerla como expresión de (ir)responsabilidad. La viabilidad de Bolivia como nación es, fundamentalmente, que los actores asuman roles de referente colectivo, susceptibles de evaluación (control social). Así, la empresa es una responsabilidad pública en el doble sentido, de la valoración social de su organización -especialmente en sus nuevas tendencias- $y$ de su aporte al sentido público ${ }^{14}$.

¿Cómo se conforma la historicidad de los actores de una sociedad? ¿Alguien debe asumir la tarea de conformación -ordenamiento- de los intereses de los actores sociales? ¿Cuáles son los roles de las elites sociales y los

13. La referencia a las elites en el Informe alcanza solamente a las empresariales.

14. Otra digresión. El mérito y la angustia bolivianos casi perma nentes son preguntarse, en cada paso, su viabilidad como nación. El mérito es el vigor de la pregunta global, que conduce a una radicalidad holística, siempre saludable. La angustia es la pérdida de sustento para una construcción progresiva de futuro. Muchas veces, de tanto preguntarse, ¿Cómo se relaciona todo con todo?, la sociedad corre discursivamente a grandes velocidades pero sin cambiar fácticamente de sitio. Puede ser que esta forma deliberativa permanente atente contra el pragmatismo del accio nar, que en los inicios del capitalismo convirtió a los (varios tipos de) valo res en sociedades industrial. 
roles de los actores políticos? ¿Cuáles son las condiciones macro-sociales de la generalización de una "cultura moderna de empresa"?

Inicialmente, cabe realizar una afirmación rotunda. No se podrá construir un sentido público del accionar de la empresa mientras sea socialmente rentable una organización pre-moderna, en que las elites oscilen entre el patrimonialismo/clientelismo y el formalismo del discurso. La condición previa es que las elites se reconozcan a sí mismas como actoras del desarrollo humano, lo que supone "adoptar posiciones” sobre la agenda del desarrollo humano.

4.- ¿En qué momento las elites pueden valorar la demanda del mercado? Un primer momento puede ser cuando la acumulación deja de basarse en la aplicación de determinadas políticas públicas, que constituyeron a actores sociales y a procesos colectivos. En este sentido, la liberalización en curso puede debilitar a una de las bases de la corrupción, con resultados macroeconómicos mensurables. Hubo casos en América Latina en que la corrupción organizada en torno a políticas públicas llegó a constituir a fracciones de clase social

Las crisis tienen un efecto "educativo" central en la conformación del mercado. La baja sustantiva en la demanda del mercado conduce a diversas formas de valoración. Probablemente, las más importantes sean reconocer las limitaciones de la organización empresarial endogámica, que ubica a la empresa también dentro de la "precariedad institucional" que vive la sociedad.

A su vez, la informalidad como modalidad de organización de la demanda también genera una valoración de la norma y el orden en la oferta, la que generalmente viene dada por la ley y la organización jurídica.

Finalmente, los empresarios apelan a la demanda como consecuencia de la baja de utilidades conseguidas invocando a mecanismos informales o abiertamente corruptos. A su vez, la organización transparente de la demanda es consecuencia, en una parte de casos y situaciones, de la anulación de la competencia a través de los mismos instrumentos informales o corruptos.

La demanda transparente permite planificar; mientras que los mecanismos informales asientan las utilidades en la especulación. Cuando las elites apelan a la transparencia de la demanda, significa que pueden autorregular a las expectativas y que pueden hacer uso legítimo del poder social que detentan ya que se ha ajustado a sus intereses.

Evidentemente, la demanda no es su componente económico. La demanda es el conjunto de circunstancias que logran articular a un conglomerado y convertirlo en una estructura compleja. Desde este punto de vista, la demanda no es, ni puede ser, el agregado de ingresos de una sociedad, especialmente de sus sectores medios y populares. La demanda existe -como una posibilidad predecible- siem pre que se integre. La integración social implica muchas formas de intercambio -material, simbólica, poder, comunicación, opinión- y muchas formas de re-estratificación, como posibilidad, dentro de los roles viables ofrecidos a los actores. Una sociedad que no ofrece opciones, no conforma a la demanda.
5.- Extender la modernización. La agenda que debe resolver la sociedad es extremadamente compleja, por las variables en las que opera la disparidad. El Informe nos dice: “...la pobreza socioeconómica y la discriminación por la diferencia sociocultural, comienzan a presionar con urgencia por la integración de lo excluido y el reconocimiento de lo negado. Es un doble requerimiento de modernización social, como extensión de la modernidad disponible a todos los miembros de la sociedad y también como una modernización efectiva en el registro de las relaciones marcadas por lo cultural".

En los períodos del ajuste, la disputa fuerte es evitar retrocesos en las modernizaciones logradas. Otra parece ser la situación, cuando las sociedades -en este caso las elites bolivianas-se plantean la extensión de las modernizaciones vigentes. Entonces, es posible sospechar que puedan existir nuevos horizontes culturales. Desde el análisis de los indicadores económicos bolivianos, no es posible afirmar que existan condiciones materiales redistributivas o que se hayan conseguido índices sustantivamente superiores de desarrollo social, sustento de la pretendida extensión. Lo que se puede sospechar, con dosis altas de justeza, es que las elites "hablan" desde una vocación por superar las crisis recurrentes y desde una situación de revaloración del equilibrio.

El equilibrio permite a las elites reconocer la modernización posible de las relaciones culturales, que es -redundantemente expresado- la modernización de las relaciones etno-culturales como componentes de la demanda. Tal vez les permita, incluso, plantearse relaciones interculturales.

6.- Empresa y política. “...la modernización de la gestión estatal en la perspectiva de la gerencia pública" no es instalar a la empresa privada en el sillón presidencial. Al contrario, desde su sentido más fuerte, tiene varios supuestos.

De un lado, puede ser el anuncio de una agenda a futuro, esto es, la modernización de la política. Esto es una visión de compatibilidad posible entre la conformación del mercado y los agentes de la política, entendidos estos como sujetos en proceso de modernización.

De otro lado, la gerencia pública es una modalidad de organización del servicio público. La posibilidad de servicio público sin prebendalismo -o de prebendalismo atenuado-supone poner en funcionamiento varias "claves" de la cultura institucional en que se pueda revalorar la capacidad estatal.

Finalmente, no puede existir gestión pública moderna sin la integración del control social como variable de la calidad del Estado y de los actores de lo público, lo que supone un acuerdo institucional.

7.- Orientación de comportamientos “...el líder aparece como impedido de intervenir en los nudos críticos que discierne. Así, la sociedad aparece como poco digerible, porque está regulada también por fuerzas anómalas y sistemáticas a su manera, capaces de reproducir y controlar su parcela de funcionamiento de los sistemas sociales y la propia convivencia. Por ende, la sociedad es objeto de presiones no tratadas, sino impuestas unas sobre o contra otras. Con ello se acentúa la dispersión o las formas no productivas del desorden". 
La anterior apreciación -que como muchas otras del Informe fue expresada dentro de un cripticismo enriquecedor- permite "jugar" con distancias y cercanías al texto, y a sus interlocutores reales.

Si leemos el texto desde los sujetos de prácticas económicas, la sociedad aparece como un imposible, ya que la falta de homogeneidad en sus mecanismos de control y regulación, la hacen improcesable en un solo sentido (de gobernabilidad y de rentabilidad). La fragmentación en muchos sistemas sociales conformaría una red de presiones inasible para los intereses de las elites. El abigarramiento posibilitaría solamente el desorden productivo.

Pero también podemos leer el texto extraído del Informe desde problemáticas generales. La política estructurada alrededor de intereses también permite lecturas adecuadas de la conformación de lo público. En lo público concurren todos los sujetos en reforma dentro de la transición en el desarro1lo. Así, la lectura de la sociedad desde los aportes concurrentes, es una modalidad de reconformar a la política.

La primera conclusión es que sería necesario conformar un espacio de lo común, en medio de lo abigarrado de las diferencias. Las diferencias se estructuran como sistemas (económicos, políticos, "institucionales", culturales), siendo que, en realidad, son subsistemas con relaciones de colaboración y antagonismo (lo formal y lo informal; lo indio y lo mestizo, por ejemplo).

La pertenencia relacionada de subsistemas dentro de un sistema es una trama a descubrir, en cuyo resultado se basa la posibilidad de un acuerdo y la aceptación orgánica de la dirección en la sociedad (el liderazgo demandado). La posibilidad del colectivo mayor (el autogobierno de la sociedad boliviana) no está en la homogenización de un orden sino en la construcción colectiva de un sentido de progreso.

8.- Regiones, no sectores. Es necesario realizar una relectura de las regiones desde la actualidad. Hace décadas, las regiones fueron esencialmente un tipo de contribución diferenciada a la nación. Las regiones disputaban hegemonías en la construcción del Estado central, las que finalmente se referían a la conformación del mercado interno.

Ahora, las regiones -según el Informe nos plantea- establecen competencias con la agenda nacional. Creo que podría estar ligado a la finalización del ciclo del efecto modernizador de la centralización. Las agendas particulares de las regiones se reconocen más en los vínculos con los nuevos mercados, en general internacionales en los que han logrado "nichos" específicos. Frecuentemente, estos mercados son regiones conformadas por fronteras, que han gestado sus propias lealtades económicas. La pregunta a futuro es, ¿ $\mathrm{Si}$ estos entornos territoriales podrán ser la base de afinidades sociales y políticas? Así, lo boliviano (lo ecuatoriano ${ }^{15}$ ) se vuelve más "abstracto" y lo regional es más "concreto".

La región es o puede ser la expresión de una fragmentación más de la nación (y una incapacidad de soberanía interna del Estado) y, al tiempo, una cohesión interna. En la región actual-vigorosamente imbuida de transnacionalidad-se concreta la idea de subsistemas políticos que se vinculan por la diferencia. La flexibilidad de la región para rearmar al sistema deteriorado junto con las transformaciones estatales es notoria. En la medida en que en los Estados nacionales es cada vez más difícil encontrar los factores de complementariedad (o de necesidad), la posibilidad de acumular capital social (confianzas que se transmiten a través de las instituciones) opera mejor en las regiones.

La viabilidad del mediano y largo plazos de la participación popular en Bolivia está asentada en la capacidad de regenerar excedentes económicos y sociales de la región, y distribuirlos. Esta capacidad redistributiva depende de la naturaleza del pacto regional que se logre y de la transparencia con la que se refleje en la estructuración del sistema político provincial.

Con más exactitud, los subsistemas políticos departamentales deben ser rediseñados para asumir más fehacientemente la representación social emergente, los procesos de modernización local, los adelantos productivos y la vocación ciudadana local. Esto implica repensar a la forma partido, la articulación de potestades nacionales y regionales, las funciones nacionales del Estado, la incidencia productiva del gobierno local y la conformación institucional de la sociedad civil local.

Finalmente, mi tentación por comentar la tipología de regiones en función de sus actitudes frente al desarrollo humano -actitud fatalista versus actitud pro activa- cedió su lugar a la asociación entre la idea de "gobernabilidad" 16 con las regiones. Dos elementos nuevos.

De un lado, lo específico de la racionalidad/percepción regional, en la que los actores son otra forma -más compleja- de colectividad en relación con los actores sociales sectoriales. De otro lado, las microregiones o las regiones muestran una capacidad de emprendimiento y de integración social, al margen de las asociaciones clásicas de pobreza y exacerbación de las reivindicaciones. Muy probablemente, grados menores de diferenciación social -al margen del grado relativo de pobreza de ingresos- puedan asociarse mejor con condiciones productivas y generar empresas colectivas más exitosas.

\section{TRES}

1.- Nación y modernidad. En uno de sus últimos discursos, en algún acto partidario retransmitido por la televisión a todo el país, don Walter Guevara Arce ${ }^{17}$ planteaba como reto angustioso de la política boliviana, la sobrevivencia de la nación en medio de la necesidad de globalizar a la economía, como única opción de futuro. El contexto, el partido que había realizado la revolución de 1952, intentaba la dirección y el protagonismo de un nuevo proceso

15. En el caso ecuatoriano, la quiebra de todos los pactos-incluido el territorial- permite pensar que la reconformación del país puede asentarse en nuevos pactos regionales/provinciales, en que las experiencias de desarrollo local exitoso - por su autonomía en la conquista de resultadosserán pilares centrales.

16. Entendida como formación de un círculo virtuoso para la asignación de recursos en un ambiente de procedimientos democráticos.

17. Líder y uno de los fundadores del Movimiento Nacionalista Revolucionario (MNR) partido eje de la Revolución Nacional de 1952 y de la propuesta de liberalización y apertura en 1985. 
dramático: ¿Cómo ser materialmente global y subjetivamente boliviano?

Bolivia, que es un país "siempre" al borde de hechos de trascendencia (la revolución y la contrarrevolución; el socialismo y el capitalismo) se expresaba en medio de una paradoja comunicacional. El octogenario intelectual (más formador de racionalidad que de liderazgo) hablaba de los parámetros de la modernidad boliviana. Sentado, ya sin vigor físico, y envuelto en un negro abrigo, trataba de derrotar a la opacidad del contexto con los colores de la nación en baile, apelando a su capital social más importante.

A su modo, el Informe también vive aquella angustia. "En el caso boliviano, la presencia de las culturas originarias, su gran capacidad para la solidaridad, la organización social, reflexión histórica, la autovaloración simbólica, expresada en muchas luchas sociales, no ha tenido suficientes oportunidades para proyectarse en el manejo de la complejidad moderna, y de esta manera poder expandir su rica visión cósmica en los avatares de la modernidad."

E intenta, el Informe, resolver la ecuación acerca de las destrezas que deben disponer los actores de la nación para aprovechar las oportunidades de la modernización. Estas son el manejo de códigos de modernidad, el uso de información, la memoria histórica como contexto y un sistema de pertenencia propio.

Los bolivianos, munidos de su nación, serían capaces de ejercer aptitudes de sociabilidad y reflexividad para lograr “...una agenda concertada de desarrollo humano, capaz de fomentar la competitividad, la equidad y la institucionalización en la sociedad”. El objetivo: “...(la) calidad de vida en un sentido convencional, vale decir, como mayor bienestar personal y social mediante la satisfacción de necesidades básicas y mayores márgenes de realización personal. En segundo término ...(la) calidad de vida como un conjunto de capacidades o cualidades de los sujetos que les permite, precisamente, un mejor y mayor desarrollo personal en los nuevos escenarios".

2.- ¿Por qué apelar a la subjetividad? "Del lado de la subjetividad, las respuestas a la vulnerabilidad y la incertidumbre son más eficaces si se construyen sobre la sociabilidad y la reflexividad progresivas. En otras palabras, si se edifican en base a la capacidad y disposición de la gente para insertarse en redes sociales, reflexionar crítica y constructivamente sobre su situación e historia, convirtiéndose en actor deliberante dentro del sistema de toma de decisiones".

Porque "Una buena iniciativa puede fracasar si no se conocen los patios interiores del ser humano". Dicho en otros términos, la propuesta del Desarrollo Humano requiere del conocimiento de los actores, de su objetividad y de su subjetividad, para proponerles tareas de construcción institucional y de futuro viables. La actualidad reclama un fino equilibrio en la reflexión entre la forma nacional y la forma global. ¿Son los bolivianos portadores de esa posibilidad?

3.- Sociabilidad. Apelemos a algunos conceptos para ubicar el tema. La sociabilidad desarrolla sentidos de pertenencia (a una comunidad). La pertenencia (referencia) tiene que darse en un intercambio entre la construcción colectiva del "nosotros" en intercambio con los "otros". La comunidad de referencia crea una forma común ${ }^{18}$ desde la cual se interpela a otras comunidades. Mientras la comunidad conformada permanezca en los planos de la autorreferencia, no podrá establecer una sociabilidad por intercambio con otras comunidades. Mientras la nación se reconforme será imposible asir a los saberes de la globalización. ¿Hasta dónde en Bolivia el vigor nacional impide este intercambio?

La sociabilidad se convierte en una aptitud de aprehensión de lo otro, cuando el sentido de lo público se incuba en las instancias primarias de socialización. La familia crea solidaridades pero no crea ciudadanos. Como es conocido, los sentidos de derecho, deber, responsabilidad y garantía se basan en la educación acerca del sentido de lo público, en niveles de individuación de los actores familiares, en flexibilidad entre lo homogéneo sanguíneo y lo heterogéneo social y, en general, en la conformación del derecho individual como equilibrio de la conformación del derecho colectivo, éste último asociado a la nación y a la familia.

El Informe hace una minuciosa reconstrucción de la percepción de la conformación familiar de la sociabilidad, pero no de la conformación del sentido público, aquel que permite completar la fórmula de aptitudes para una socialización exitosa, tolerante, confiable, trasmisible y, fundamentalmente, reflexiva de la globalidad desde una base nacional. Esto que me permito denominar como el "consumo de las instituciones".

La capacidad comunitaria del mundo privado boliviano es extraordinaria. Ha desempeñado un rol de extraordinaria fortaleza en la transición, como instancia de refugio y de protección frente a la crisis y el ajuste. La capacidad de adaptación del mundo privado de los sectores subalternos de Bolivia es muy creativa. Pero subsiste la duda de, ¿Si es una capacidad suficiente para insertarse en formas de modernidad avasallantes en el pensamiento desde sus propios pies culturales?

El mismo Informe se replantea, con justeza, en la vehemencia de algunas de sus afirmaciones: "...los bolivianos tienen un alto grado de sociabilidad, que se expresa en la facilidad para relacionarse con los demás. Sin embargo, existe cierta desconfianza de los que otro pueda hacer en el espacio público, particularmente en la ciudad. La "disposición vinculante" es un potencial para el desarrollo humano dentro de la sociedad boliviana, pero que tiene que ser activado y extendido para que abarque esferas que trasciendan los límites de la familia".

La capacidad de "vivir" el mundo público muchas veces se atropella con un traslape inintencional del mundo privado. Muchas esferas del mundo público se hacen a imagen y semejanza del mundo privado, por lo cual se configuran como falta de orden. La familia no es orden público. Las estructuras del parentesco no generan orden ni estabilidad públicos. Suelen desbordar el orden público en configuración y se imponen desde su lógica agregativa. Un caso claro es la débil conformación de la autoridad boliviana y

18. ¿Hasta dónde homogénea? 
la facilidad con que se consume la legitimidad sin réditos en la formación de confianzas con el sistema político a largo plazo.

Refiriendo al mismo problema desde otro sentido, el Informe plantea que se producen "Mutación(es) de roles sociales que el sistema no logra incorporar". Esto es un desencuentro entre los actores de los cambios y las estructuras institucionales que deberían soportarlos. Desde allí, el problema está también en la conformación de lo público.

4.- Reflexividad. La pregunta central pudiera ser, ¿ Son la deliberación y el contacto social tolerante partes constitutivas de las relaciones sociales bolivianas? La violencia (las diversas formas que adquiere) fue, en general, la vía de "solución" de la forma nacional. Estuvo ligada a las bases productivas de la nación, especialmente, la minería. ¿Qué es lo que ha cambiado en la Bolivia actual, que permita asentar una cultura reflexiva encaminada a la construcción deliberativa del futuro; de la forma estratégica de la política?

Las culturas (políticas) andinas son gestuales. El valor del "gesto" sobresale frente al valor de la palabra. Por ello ha sido tan difícil construir ciudadanía; porque la escena pública procesada por los antecedentes familiares, comunitarios, gregarios -oligárquicos o subalternos-, codificados. Los códigos que despliegan los gestos en los sistemas políticos andinos, no están inscritos, por necesidad, en un código traducible de democracia. La polisemia de las nociones de acuerdo y participación es un ejemplo permanente. A los sistema políticos les espera, más bien, una larga construcción de puentes de diálogo intercultural e interinstitucional.

Cabe también indagar acerca de las formas de capital social, en las cuales es tan rico Bolivia. El sentido al que apunta el capital social es asentarse en formas de democracia no verbal. Son formas simbólicas ya que la confianza es creencia, incluso en las formas más avanzadas de legitimidad democrática. Esto nos plantea articulaciones complejas entre el mundo simbólico y la democracia, justamente para la vigencia de sus componentes deliberativos.

Como una última digresión, cabe opinar que el Informe obtiene una conclusión excesivamente convencional: " $\mathrm{La}$ sociabilidad es más intensa entre los pobres del campo, mientras que la reflexividad, referida al manejo de los códigos de una modernidad compleja, está más vigente entre los jóvenes de estratos medios y altos urbanos." El llamado de atención acerca de la convencionalidad de la afirmación trata de prever conclusiones prácticas acerca de la socialización y del desarrollo.

El tránsito del gesto a la palabra -entonces a la deliberación- es complejo pues no se trata de la introducción "civilizatoria" de nuevos códigos, que tampoco son los que hicieron a las "tempranas" democracias más al sur del cono. Se trata de un lenguaje político sustentado en difíciles ecuaciones de valores sociales de sociedades en tránsito en el desarrollo. Son varios tipos de relaciones: individuo-sociedad; sociedad global-sociedades particulares; individuo-individuo.

La posibilidad de que la sociedad tenga una visión sobre sí misma, como condición de un tratamiento deliberativo de las diferencias, es difícil. La relación especular de los gru- pos sociales se consigue luego de una activa relación con otros grupos, la que permite justamente una agenda compleja de desarrollo, que pueda devenir en agenda de desarrollo humano. En caso contrario, la relación especular no supera la autorreferencia.

5.- Una distinción. Quisiera diferenciar entre la vocación que existe en Bolivia por diseñar un sistema político basado en la deliberación respecto de las condiciones y aptitudes de los actores para lograrlo. La disposición (aspiración) para el diálogo existe, aunque, al mismo tiempo, son bastante más grises las actitudes y prácticas de los actores.

Las elites, como ha sido parte de este comentario, muestran dificultades para entender sus compromisos con la sociedad y el mercado. La gente se acerca a las instituciones, pero aún no se identifica con ellas. El Municipio es la institución que encarna al Estado, pero su "juventud" le impide asumir las funciones que esta situación demanda. El capital social acumulado a nivel local no encuentra los cauces para convertirse en la legitimidad nacional. La socialización familiar todavía no se transforma en creadora de actores con derechos a su interior y en la sociedad. Las culturas política e institucional se transforman, pero sus ciclos -hasta lograr la eficacia requerida por el sistema político- todavía están distantes de alcanzar la sustentabilidad.

Esta "vuelta" crítica tiene por objeto señalar la plena coincidencia de este comentario con el rumbo estratégico del Informe tanto como apoyar, con la duda acerca de la situación actual, a la construcción de sistemas de seguimiento y observación sociales de los temas planteados, al tiempo que plantear la necesidad de incorporar variables abiertas por cada coyuntura.

Un observatorio social en Bolivia debe asumir la rica tarea de evaluar como se construye la "ecuación" para democracia deliberativa entre las variables pertinentes. De este modo, se ubica en el plano de medida de la estrategia objetiva, real- que los actores utilizan para ubicarse en la construcción (o destrucción) de sus horizontes de democracia deliberativa.

\section{BIBLIOGRAFÍA}

ARDAYA, Gloria y Luis VERDESOTO (1994): Una racionalidad politica en construcción. La Paz: ILDIS.

Calderon, Fernando y Alicia SzMukler (1999): La política en las calles. La Paz: Plural.

Calderon, Fernando y Roberto, Laserna (1983): El poder de las regiones. Cochabamba: CERES-CLACSO.

PNUD (2000): Informe de desarrollo bumano en Bolivia. La Paz: PNUD

VERDESOTO, Luis (1998): "Los conceptos de participación y descentralización mirados desde el caso boliviano”. En: Revista del Centro Latinoamericano de Administración para el DesarroIlo, CLAD, "Reforma y Democracia" N- 12.

Verdesoto, Luis (1996): Temas para una sociedad en crisis. ¿Es posible gobernar desde los consensos? Quito: Esquel - Foro de la ciudadanía.

Verdesoto, Luis, Gloria Ardaya, Roque EsPINOZA y Fernando GARCIA (1995): Rostros de la Familia Ecuatoriana. Quito: UNICEF. 